\title{
Vibrations in Leaking Spherical Valves with Annular Seal ${ }^{+}$
}

\author{
Hesham Awad 1,*, Jorge Parrondo ${ }^{2}$ and Víctor González ${ }^{3}$ \\ 1 Mechanical Engineering Power department, Arab Academy for Science, Technology \& Maritime Transport, \\ Alexandria 21500, Egypt \\ 2 Energy Department, Universidad de Oviedo, 33204 Gijón, Spain; parrondo@uniovi.es \\ 3 TSK Group, 33203 Gijón, Spain; uo212192@uniovi.es \\ * Correspondence: Heshamsaber12@gmail.com \\ + Presented at the 2nd International Research Conference on Sustainable Energy, Engineering, Materials and \\ Environment (IRCSEEME), Mieres, Spain, 25-27 July 2018.
}

Published: 21 November 2018

\begin{abstract}
Hydroelectric power plants are used worldwide to cover varying electricity demands. The Salime hydroelectric power plant, which is located at Asturias, Spain, has four hydro turbines with a total design capacity of $128 \mathrm{MW}$. Each turbine has a ball valve with two maintenance seals to ensure a closure as complete as possible when the group ceases to operate. Unfortunately, at some occasions the seals did not really perform their sealing function properly, but started to develop periodic vibrations of indefinite duration. This phenomenon generates periodic leakage flow as well as high amplitude pressure fluctuations in the penstocks, which are not acceptable. This phenomenon corresponds to the field of flow-induced vibrations, in particular to the type of self-excited vibrations. The purpose of the research now reported was to develop a simplified theoretical model that can explain the excitation mechanism for the seal vibrations and that can estimate the behavior of the hydro-mechanical system depending on the relevant geometrical and physical parameters. In order to calculate the pressure and flow rate fluctuations, the energy equation for unsteady, unidirectional, incompressible and viscous flow has been applied along each pipe of the hydraulic system, together with continuity considerations at each pipe junction and the seal equation of motion. The perturbation technique has been used to solve the system variables. The mathematical model was solved by means of a specially designed MATLAB code, which allows simulating the time evolution of the annular seal vibration as well as the unsteady flow and pressure induced throughout the system for different system configurations. The results show that the system stability depends on the behavior of the hydraulic pressure force acting on the seal and the gap flow rate after system disturbance. Besides, the results obtained support that, at standing group situation, seal vibrations are less prone to occur when operating at either low reservoir energy level or very large reservoir energy level.
\end{abstract}

Keywords: flow induced vibration; self-excited vibrations; Salime hydroelectric power plant; leakage flow; pressure fluctuation; perturbation technique

\section{Introduction}

The Salime hydroelectricity power plant is an impoundment plant with four hydraulic groups, each with a penstock from the intake reservoir and a Francis turbine, with a total design capacity of $128 \mathrm{MW}$ [1]. At a short distance upstream from the turbine distributor there is a ball valve (Figure 1) intended to ensure a closure as complete as possible when the group ceases to operate. For that purpose, the valve has two maintenance seals: a fixed one at the ball entrance and a sliding annular seal at the ball exit, which can move in the axial direction. The sliding seal can be tightened on the 
ball by applying pressure forces on the annular seal obtained from the hydraulic system itself, such as shown in Figure 2.

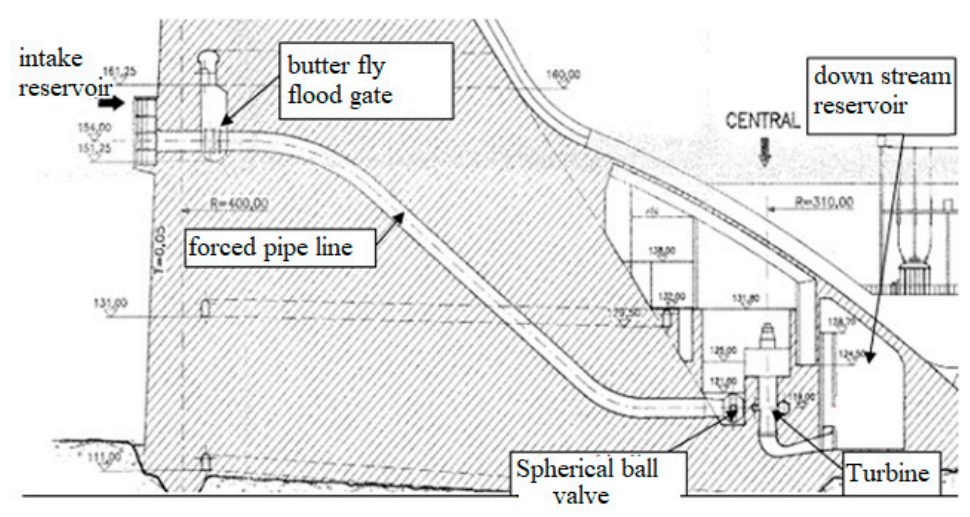

Figure 1. Profile of the Salime Hydroelectric Power Plant.

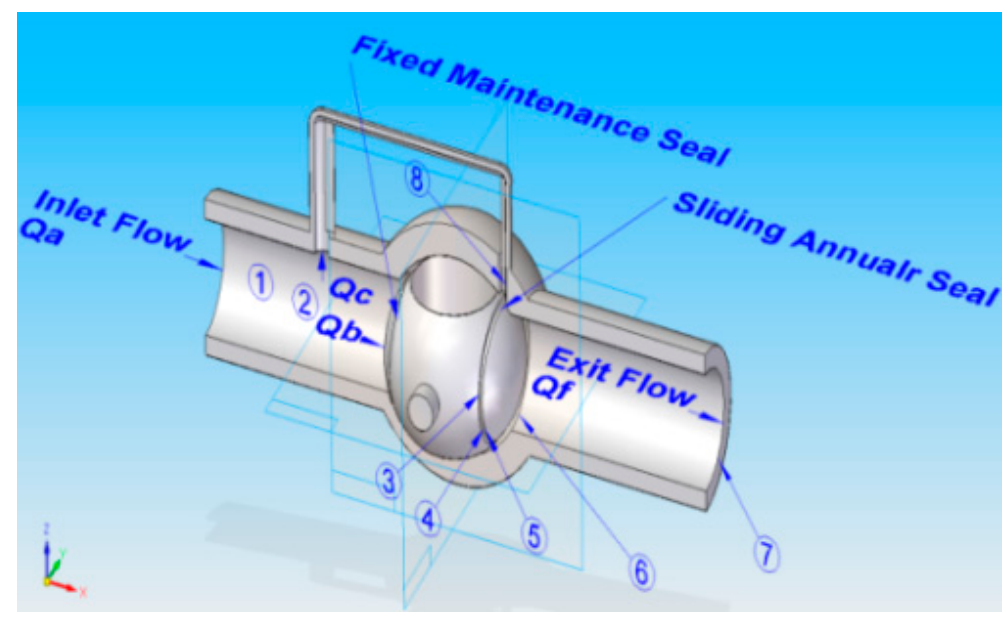

Figure 2. Simplified diagram of the closed valve with duct for application of pressure on the sliding annular seal.

However, it was noticed on different occasions that, at a standing group situation with the ball valve closed, the annular seals were prone to develop periodic vibrations of indefinite duration accompanied by periodic leakage flow and high amplitude pressure fluctuations in the penstocks, which are not acceptable. The purpose of the research now reported was to develop a simplified theoretical model that can explain the excitation mechanism for the seal vibrations and predict the behavior of the hydro-mechanical system depending on the relevant geometrical and physical parameters.

\section{Seal Specifications}

As an initial hypothesis, it was assumed that the phenomenon was related to the existence of leakage flow. In particular, the annular seal was considered to be slightly bent relative to the seating plane, so that a portion of the seal presents some clearance leading to leakage (Figure 3). 


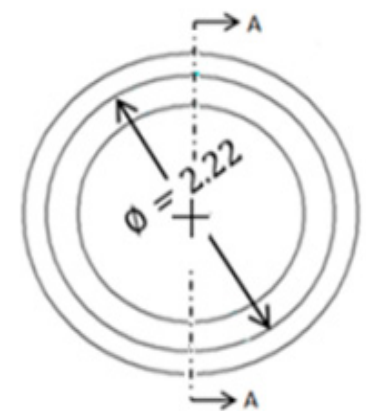

(a)

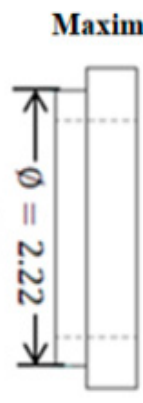

(b)

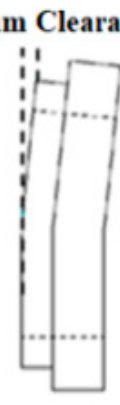

(c)

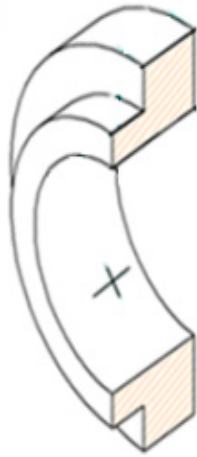

(d)

Figure 3. (a) Annular seal front view; (b) Un-deformed annular seal side view (c) Deformed annular seal side view; (d) Annular seal section view.

In order to solve the equivalent $1 \mathrm{D}$ equation of motion that governs the flexural vibrations of the annular seal, first the relevant structural properties have to be established. This includes equivalent stiffness, mass and damping parameters. The annular seal stiffness is the ratio between the applied load and average deflection [2], as in Equation (1), where the gap length is $L_{0}, \theta_{\text {gap }}$ is the gap angle and $\theta_{\max }$ is the total annular seal angle.

$$
\mathrm{K}_{\text {seal }}=\left|-\frac{720 \mathrm{EI}}{\mathrm{L}_{0}^{3}}\right| \quad \mathrm{L}_{0}=\mathrm{L}_{\max } \frac{\theta_{\text {gap }}}{\theta_{\max }} \quad \mathrm{L}_{\max }=\pi \emptyset
$$

The equivalent mass of the annular seal corresponding to the gap angle can be computed as:

$$
\mathrm{M}_{\text {seal }}=\mathrm{M}_{\text {seal }} \frac{\mathrm{L}_{0}}{\mathrm{~L}_{\max }}=\mathrm{M}_{\text {seal }} \frac{\theta_{\text {gap }}}{\theta_{\text {max }}}
$$

Finally, the equivalent damping coefficient can be obtained with Equation (3), after imposing a value for the damping ratio [3]:

$$
\mathrm{C}_{\text {seal gap }}=2 \xi \sqrt{\mathrm{K}_{\text {seal_gap }} \mathrm{M}_{\text {seal_gap }}}
$$

\section{Theoretical Model and Procedure}

It is believed that the case of interest corresponds to the type of flow-induced vibration known as Movement Induced Excitation (MIE) [4], in which the fluid dynamic force is generated and supported by the oscillatory motion of the vibrated seal. According to Figure 2, the pressure and flow rate at different locations of the system is to be modeled by using the energy equation for unsteady, unidirectional, incompressible and viscous flow [5] together with the continuity equation applied at junctions [5] and with the equation of motion of the seal [3]. This produces a system of differential equations which has been linearized (Taylor series) to consider low amplitude fluctuations about an equilibrium position (perturbation technique). The mechanical model is solved in two steps: fist the steady state terms of the equations and then the unsteady terms, which are proportional to the instantaneous seal displacement.

\section{Results}

Figure 4 shows a case that happens to be dynamically stable, since the seal vibration as well as the fluctuations of the flow variables (flow rate, energy level and seal force) decay progressively after an initial perturbation from equilibrium. In this case the seal vibrates at about $26 \mathrm{~Hz}$ and the amplitude reduces to less than half in just 6 oscillations. 


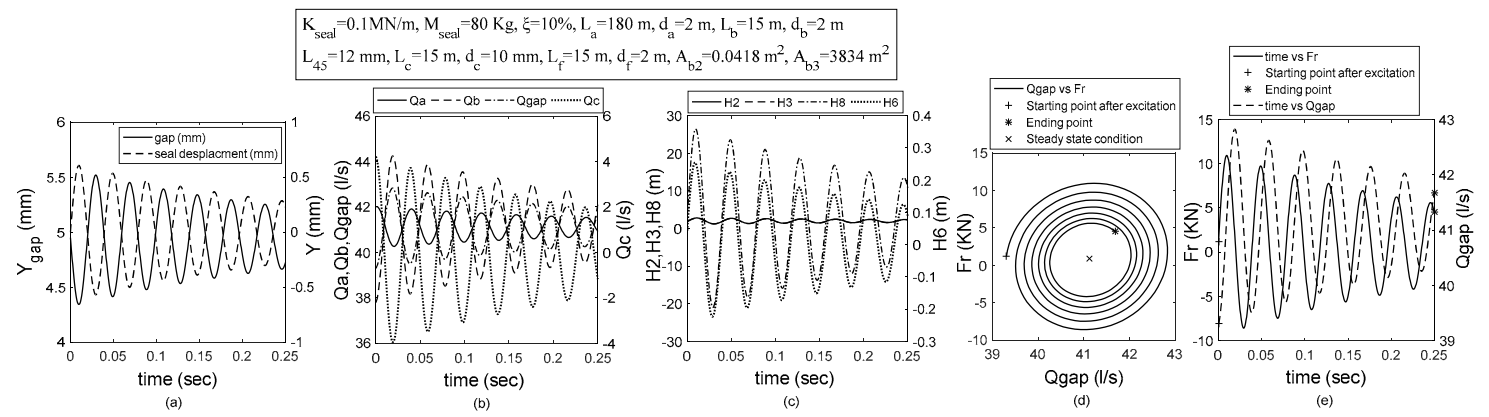

Figure 4. Mechanical system simulation during $0.25 \mathrm{~s}$ for an input reservoir energy of $2 \mathrm{~m}, 65^{0}$ gap angle and seal initial velocity of $0.1 \mathrm{~m} / \mathrm{s}$. (a) Seal gap and displacement; (b) Flow rate at different sections; (c) Total energy level at different sections; (d,e) Hydraulic pressure force on the seal and leakage flow.

Figure 5 shows the simulation for a system with the same parameters except the head of the reservoir, which is $30 \mathrm{~m}$. The frequency of the oscillations is similar to those of Figure 4 but now the system happens to be dynamically unstable as the oscillation amplitude keeps on increasing during the simulation. The same happens with the fluctuations in flow-rate and energy throughout the system and with the pressure force on the seal. Also, in comparison with the $2 \mathrm{~m}$ reservoir head case, the mean gap has reduced from about 5 to $4 \mathrm{~mm}$ whereas the average flow rate through the gap is now 3 times higher, because of the higher pressure upstream the valve.
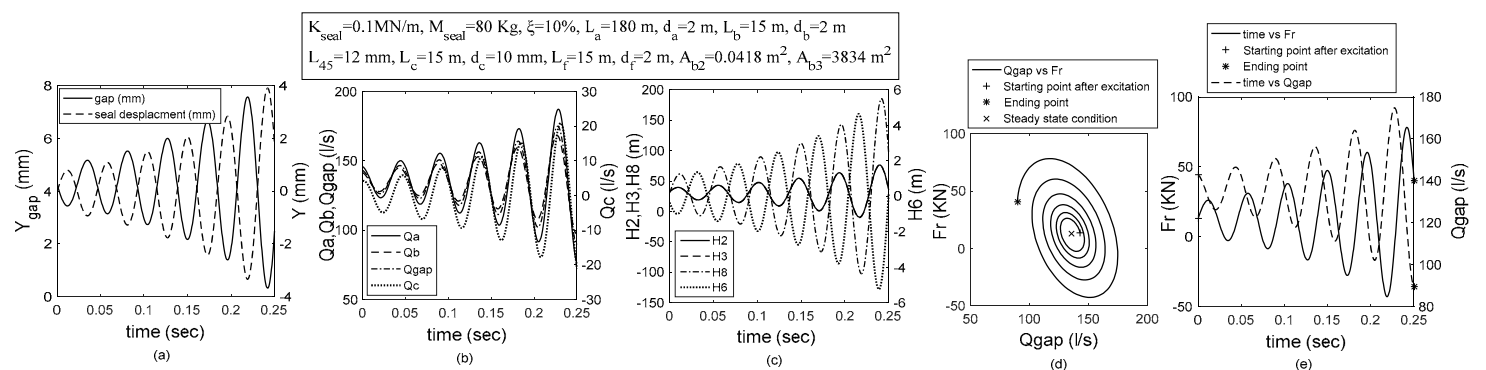

Figure 5. Mechanical system simulation during $0.25 \mathrm{~s}$ for an input reservoir energy of $30 \mathrm{~m}, 65^{0}$ gap angle and seal initial velocity of $0.1 \mathrm{~m} / \mathrm{s}$. (a) Seal gap and displacement; (b) Flow rate at different sections; (c) Total energy level at different sections; (d,e) Hydraulic pressure force on the seal and leakage flow.

Figure 6 shows that, for the same system parameters, increasing the input reservoir energy level above $203.6 \mathrm{~m}$ makes the system become statically stable, because the average hydraulic force on the seal gets high enough to totally unbend the annular seal and reduce the gap clearance to zero. In consequence there is no leakage flow and no vibration excitation.

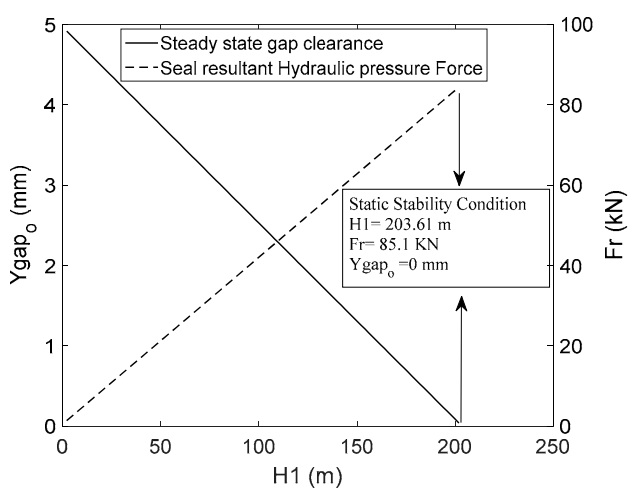

Figure 6. Steady state gap clearance as a function of the input reservoir energy level. 


\section{Conclusions}

A theoretical model has been proposed to represent the hydro-mechanical system that governs the motion of the annular seal of large ball valves like those of hydro plants. The model assumes that there is some leakage flow through a gap between seal and seating. With this model, the stability of the system can be appreciated by monitoring any variable after a small initial perturbation with respect to equilibrium. Seal vibrations are less prone to occur when operating at low input reservoir energy level, as the leakage flow rate is small and the inertia corresponding to this leakage is small too. This leads to a dynamically stable system, as the flow rate and pressure oscillations get damped as in Figure 4. However, increasing the input reservoir energy level makes the leakage flow rate increase too, so that the inertia effects in the system get more important. As a result, the system turns eventually to be dynamically unstable, with flow rate and pressure fluctuations that keep on growing along time as in Figure 5. On the other hand, increasing the input reservoir energy level brings about an increment of the mean pressure forces applied on the seal, so that the gap clearance may eventually become zero. In this case the mechanical system is considered statically stable, as there will be no leakage and the seal cannot undertake vibrations (Figure 6).

Acknowledgments: The authors acknowledge the financial support received from Instituto Universitario de Tecnología de Asturias (Spain) under project SV-15-GIJÓN-1-10, as well as the Erasmus scholarship grant KA107 awarded to Hesham Awad. Special thanks are given to Alberto Rúa-Figueroa, manager of the Salime hydropower plant, for his collaboration and assessment.

\section{References}

1. Available online: http://www.saltosdelnavia.com/en/salime-hydropower-plant_57936.html (accessed on 15 June 2018).

2. Budyans, R.G.; Nisbett, J.K.; Shigley, J.E. Shigley's Mechanical Engineering Design, 9th ed.; McGraw-Hill: New York, NY, USA, 2011

3. Raw, S.S. Mechanical Vibration, 6th ed.; Pearson: Harlow, UK, 2017

4. Rockwell, E.N.D. Flow-Induced Vibrations-an Engineering Guide; Editorial A. A. Balkema: Rotterdam, The Netherlands, 1994.

5. Cimbala, J.M.; Cengel, Y.A. Fluid Mechanics Fundamentals and Applications, 2nd ed.; McGraw-Hill: New York, NY, USA, 2010.

(C) 2018 by the authors. Licensee MDPI, Basel, Switzerland. This article is an open access article distributed under the terms and conditions of the Creative Commons Attribution (CC BY) license (http://creativecommons.org/licenses/by/4.0/). 